\title{
Conservative management in a case of retained adherent placenta in a primigravida patient
}

\author{
Annal Vaidya*, Shruti Panchbudhe, Meena Satia
}

Department of Obstetrics and Gynecology, G. S. Medical College and King Edward Memorial Hospital, Mumbai, Maharashtra, India

Received: 12 May 2017

Accepted: 10 June 2017

*Correspondence:

Dr. Annal Vaidya,

E-mail: annalvaidya911@gmail.com

Copyright: (c) the author(s), publisher and licensee Medip Academy. This is an open-access article distributed under the terms of the Creative Commons Attribution Non-Commercial License, which permits unrestricted non-commercial use, distribution, and reproduction in any medium, provided the original work is properly cited.

\begin{abstract}
Morbidly adherent placenta is a serious and a catastrophic pregnancy complication. In this condition, the placenta penetrates deeply inside the uterine walls and is not separated after delivery of the baby. Reporting herewith a case of a primigravida who had undergone Emergency lower segment Caesarean section at a private hospital for severe pregnancy induced hypertension with IUGR and then was referred to Tertiary Care hospital with placenta left in-situ due to non-separation of the placenta at the time of caesarean section. Conservative management was given using Methotrexate which is an anti-metabolite alternatively with Leucovorin (Folinic acid) and followed up with serial ultrasonography with Doppler for placental size and volume and beta-HCG levels which showed a decreasing trend respectively.
\end{abstract}

Keywords: Adherent placenta, Conservative management, Methotrexate

\section{INTRODUCTION}

Adherent placenta is a leading cause of maternal mortality world over accounting for $7-10 \% .^{1}$ Adherent placenta are classified according to degree of invasion into the myometrium as placenta accreta, placenta increta and placenta percreta. Placenta percreta is the most severe but least common one. ${ }^{2}$ The various high risk factors for adherent placenta are 2 or more Caesarean deliveries, advanced maternal age ( $\geq 35$ years), those with placenta praevia, second-trimester serum levels of AFP and free $\beta$ human Chorionic Gonadotrophin greater than 2.5 multiples of median, three previous uterine surgery, previous uterine curettage, multiparty and high gravidity. ${ }^{3-5}$ Placenta accreta occurs in approximately 1 of 2500 deliveries. $^{6}$ In our case the patient was elderly primigravida without any risk factors for adherent placenta and the occurrence of adherent placenta in such cases is quite rare. She was a known case of preeclampsia but it by itself is not known to increase the incidence of adherent placentation. Only three such other cases of primigravida patients with adherent placenta have been reported in literature and are mentioned below.

\section{CASE REPORT}

A 33-year-old patient was referred to the emergency services of Tertiary care hospital on Day 1 of Emergency lower segment Caesarean section, the indication of section being severe pre-eclampsia and Intra uterine growth restriction, which was done 6 hours back at a private hospital with suspected adherent placenta (which was not diagnosed on the antenatal ultrasonography) and was left in situ for further management and treatment. As per the operation notes the placenta was found to be densely adherent to the left cornu and the fundus on the anterior wall and was not separated by controlled cord 
traction during caesarean section, so a suspicion of adherent placenta was made. In view of above intraoperative findings any further attempt to separate the placenta were abandoned and cord was clamped and cut, followed by uterine closure and closure of the abdominal incision and referral of the patient to tertiary care centre. On arrival to the emergency services, she was conscious, oriented, afebrile, pulse of 90/minute, BP of $150 / 100 \mathrm{mmHg}$ with mild pallor and grade 1 oedema feet. On per abdomen examination uterus was 24 weeks, well contracted without guarding, tenderness or rigidity. Pfannensteil incision which was sutured using subcuticular Vicryl sutures was seen. On per vaginum examination uterus was 24 weeks, os was one finger open and minimal bleeding was present. All her blood investigations were sent including blood grouping and cross-matching and the reports were haemoglobin 10.3 gm\%, CBC 15000, platelets 1.52 lakhs, PT 13.7 and INR 0.97. Liver and renal function tests were normal. She was started on broad spectrum antibiotics which included piperacillin-tazobactam $4.5 \mathrm{gm}$ bd, metronidazole $100 \mathrm{mg}$ tds and gentamycin 80mg bd started which were continued for 7 days. In view of patient having high blood pressure during antenatal and postpartum period she was continued on anti-hypertensives, tablet Labetalol $100 \mathrm{mg}$ bd and Tablet Nifedepine 10mg qid were continued and eventually tapered and omitted in the postpartum period gradually over 7 days when the blood pressure returned back to normal. Ultrasonography of the abdomen and pelvis at tertiary care institution showed retained placenta of $270 \mathrm{cc}$ but there was a suspicion of adherence for which MRI pelvis was advised. MRI plates confirmed retained adherent placenta (diagnosed by the absence of Nettlebach's layer in the myometrium) in the fundal and left lateral wall without any evidence of placenta percreta.

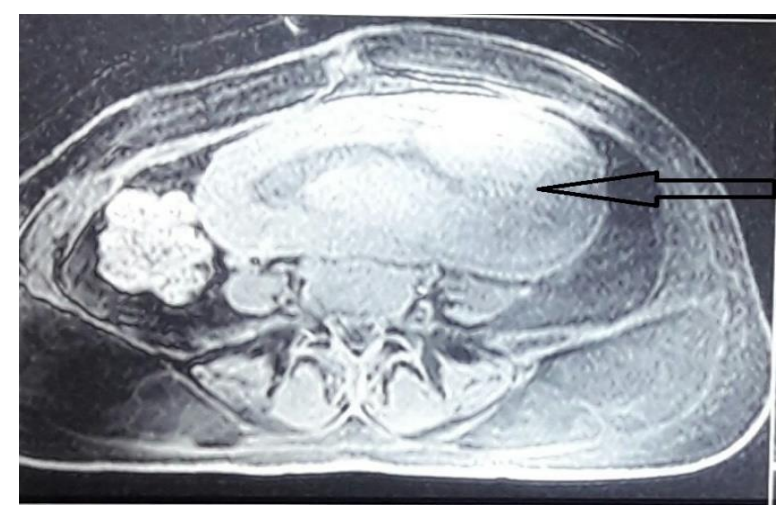

Figure 1: MRI plate showing adherent placentapointer.

The first $\beta-\mathrm{HCG}$ at the time of admission was 36038 IU. In view of the above MRI findings and patient being haemodynamically stable a decision for conservative medical management was made after obtaining informed consent from the patient and her relatives. The patient was given 1 cycle of intramuscular Injectable Methotrexate (dosage of $1 \mathrm{mg} / \mathrm{kg}$ ) 60mg, 5 doses on day
1,3,5,7,9 with Injectable Leucovorin (dosage of $0.1 \mathrm{mg} / \mathrm{kg}$ ) $0.6 \mathrm{mg}, 5$ doses on day $2,4,6,8,10$. During this course of treatment patient was serially monitored with LFT, CBC and Platelets in view of hepatotoxicity and bone marrow toxicity of Methotrexate. Patient was also advised to stop breast feeding this treatment course as Methotrexate is secreted in the breastmilk. Beta-HCG was repeated on day 14 and was found to be 12085 IU. Also, ultrasonography with Doppler flows showed a reduction in placental size and volume from $270 \mathrm{cc}$ to $180 \mathrm{cc}$

Patient was discharged on Day 16 on haematinics and calcium supplements and was asked to follow up on OPD basis 2 weeks later with ultrasonography for placental volume and beta-HCG report. Patient reported to the OPD on Day 35 and ultrasonography was suggestive of a residual placental volume of $180 \mathrm{cc}$ and beta-HCG values of 1993 IU. She was asymptomatic at that time with no complaints of bleeding per vaginum or fever and therefore was asked to again come after 2 weeks for follow up with b HCG and Ultrasonography reports. However, she presented on Day 39 with complaints of bleeding and passage of clots per vaginum. Patient was readmitted and all her blood investigations were sent and she was started on Ceftriaxone (1gm bd) and metronidazole (100mg tds). On admission patient had three episodes of fever for which her fever profile was sent which was normal and her CBC was 16800. Fever was managed by antibiotic coverage. Her repeat ultrasonography done showed a placental volume of $130 \mathrm{cc}$ and beta-HCG values of 698 IU. She was given a $2^{\text {nd }}$ cycle of intramuscular Injectable Methotrexate $60 \mathrm{mg}$, 3 doses (dosage of $1 \mathrm{mg} / \mathrm{kg}$ ) on day 1, 3, 5 with Injectable Leucovorin $0.6 \mathrm{mg}$, 3doses (dosage of $0.1 \mathrm{mg} / \mathrm{kg}$ ) on day 2, 4, 6 as patient was symptomatic and sonography and beta-HCG reports showed a slow decrease in placental volume.

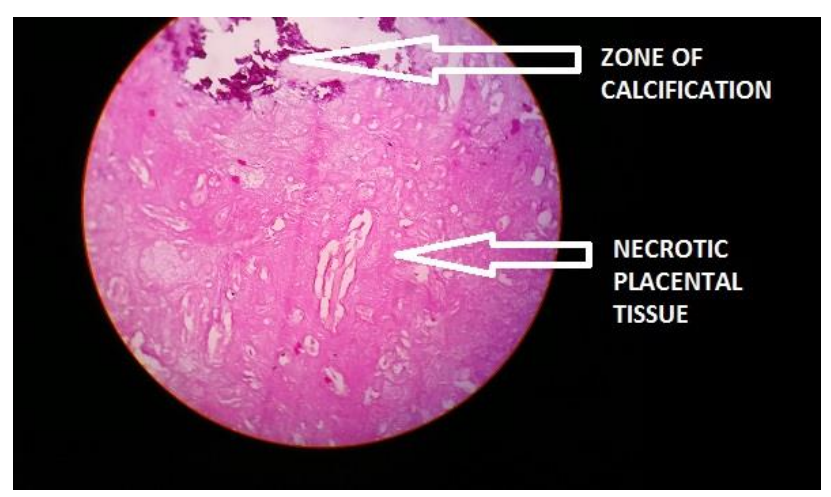

Figure 2: Histopathological evidence of placental tissue passed per vaginum.

USG after the $2^{\text {nd }}$ cycle of Methotrexate showed placental volume of 130cc Day 40 and B HCG was 698. She was asymptomatic and was discharged for the second time on Day 47 without any complaints. The patient came for follow up to the OPD, the beta- HCG levels dropped 
steeply to less than 2 IU and placental volume was $60 \mathrm{cc}$ on sonography. She was admitted the third time on Day 93 i.e. 3 months after delivery as she again had complaints of passing some fleshy mass per vaginum. On examination, the placental tissue could be felt in the cervix. On Day 95 she expelled a fleshy mass around $10 \mathrm{gm}$ per vaginum which was sent for histopathology which confirmed it to be placental tissue. Sonography was done which showed a placental tissue of just 4cc in the left cornual area with high vascularity. The patient was discharged on Day 98 without any complaints.

Table 1: Serial Beta-HCG and Placental volumes.

\begin{tabular}{|lll|}
$\begin{array}{l}\text { Day of } \\
\text { Emergency } \\
\text { LSCS }\end{array}$ & Beta-HCG levels (in IU) & $\begin{array}{l}\text { Placental } \\
\text { Volume } \\
\text { (in CC) }\end{array}$ \\
\hline 2 & 36038 & 270 \\
\hline 9 & 25128 & 270 \\
\hline 14 & 12085 & 180 \\
\hline 32 & 1993 & 180 \\
\hline 40 & 698 & 130 \\
\hline 63 & $<2$ & 60 \\
\hline
\end{tabular}

This Primigravida patient was managed conservatively using anti-metabolite agent Methotrexate with Leucovorin rescue without any surgical intervention.

\section{DISCUSSION}

The incidence of adherent placenta has risen from $5.4 \%$ to $46.5 \%$ becoming a major indication for peripartum hysterectomy. ${ }^{7}$ The incidence is rising primarily because of the rise in caesarean delivery rates. Because of the rare occurrence of adherent placenta in a patient who was pregnant for the first time without any known risk factors.

Ultrasonography is the most easily available and primary modality for the diagnosis of adherent placenta. ${ }^{8}$ If the position of the gestational sac is lower than usual or the myometrium in the area of the scar seems thinned out, it is an early $1^{\text {st }}$ trimester sign of possible future adherent placenta. ${ }^{9}$ Placenta accreta on ultrasound Doppler study can be identified by the absence of the hypo-echoic clear area in the retro-placental zone. ${ }^{10}$ MRI is done only in case the USG findings are not conclusive or the location of the placenta is posterior.

The surgical technique used involves peri-operative placental localization by ultrasonography and the uterine incision is taken transversely just below the upper segment i.e. above the upper border of the placenta; pelvic devascularisation for control of haemorrhage and non-separation of the placenta (left in-situ). ${ }^{11}$ A planned caesarean hysterectomy, ideally at 35-36 weeks should be done for placenta percreta/accreta. A combined approach by a team of obstetricians, neonatologists, anaesthesiologists, urologists and even blood bank personnel is necessary. ${ }^{12}$ Conservative management can be used of leaving the placenta in-situ with minimal resection and use of anti-metabolite drugs. Conservative management can be used only if the patient is hemodynamically stable and willing to accept a risk. Conservative management is associated with severe postpartum haemorrhage, post-operative coagulopathy and infection that may require re-laparotomy and hysterectomy. ${ }^{11}$ The role of methotrexate in post-partum management adherent placenta is uncertain, though some cases have been reported. Methotrexate when administered systemically reduces placental vascularity leading to necrosis and rapid resolution although the route of administration, treatment schedule and total number of doses prescribed varies. Such adherent placenta left in situ may either be completely expelled per vaginum in around 1 week or may spontaneously undergo total resorption in around 20-24 weeks. Preoperative placement of occlusion catheter with intraoperative balloon occlusion of the aorta, common iliac (most commonly internal iliac arteries), hypogastric and uterine arteries has been found to control obstetric haemorrhage. Surgical peripartum hysterectomy is the recommended line of management, conservative approach can be chosen if alternative facilities are available and the patient is willing to accept a certain amount of risk.

Previously reported cases of primigravida patients with adherent placentation are as follows. First such reported by Arnadottir BT et al with successful conservative management with methotrexate along with a healthy infant. ${ }^{13}$ Kinoshita et al from Japan reported a case of spontaneous rupture of uterus due to placenta percreta in a primigravida, wherein there was no risk factor associated. ${ }^{14}$ The last was by Bhuvaneshwari Rajkumar et al which was again managed using methotrexate. ${ }^{15}$

Management of placenta accreta is based upon amalgamation of different modalities available and ultimately the patient's choice. Conservative management reduces the peripartum haemorrhage and allows patients to preserve the child bearing capacity. Side effects of this therapy are secondary haemorrhage, sepsis, long-term follow-up. The interval between treatment and resolution varies from case to case, so careful follow-up of these patients is important as was done in our case. $\beta$-human chorionic gonadotropin serial measurement only gives an approximate estimate about the placental volume. Conservative management has some disadvantages, including postpartum infection, treatment failure, and restrictive follow-up but should be considered in selected cases.

\section{CONCLUSION}

The life-saving modality of management is the early diagnosis of this condition. A multi-level and multidisciplinary approach is the line of management. An increase in the number of caesarean sections and uterine curettages have increased the rate of abnormal placentation. Hence it is essential to optimise the protocols required for management of these procedures. 
Peripartum Hysterectomy, the definitive management for adherent placenta terminates the woman's reproductive capacity though it is a life-saving procedure.

Funding: No funding sources

Conflict of interest: None declared

Ethical approval: Not required

\section{REFERENCES}

1. Chandraharan E, Rao S, Belli AM, Arulkumaran S. The Triple-P procedure as a conservative surgical alternative to peripartum hysterectomy for placenta percreta. Int J Gynaecol Obstet. 2012;117(2):191-4.

2. Konijeti R, Rajfer J and Askari A. Placenta Percreta and the Urologist. Rev Urol. 2009;11(3):173-6.

3. Wu S, Kocherginsky M, Hibbard JU, Abnormal placentation twenty-year analysis. Am J Obstet Gynecol. 2005;192(5):1458-61.

4. Hung TH, Shau WY, Hsieh CC, Chiu TH, Hsu JJ, Hsieh TT. Risk factors for placenta accrete. Obstetr Gynecol. 1999;93(4):545-50.

5. Jacques SM, Qureshi F, Trent VS, Ramirez NC. Placenta accreta Mild cases diagnosed by placental examination. Int J Gynecol Pathol. 1996;15:28-33.

6. Miller DA, Chollet JA, Goodwin TM. Clinical risk factors for placenta previa-placenta accreta. Am J Obstetr Gynecol. 1997;177(1):210-4.

7. Flood KM, Said S, Geary M, Robson M, Fitzpatrick $\mathrm{C}$, Malone FD. Changing trends in peripartum hysterectomy over the last 4 decades. Am J Obstet Gynecol. 2009;200(6):632e1-6

8. Hudon L, Belfort MA, Broome DR. Diagnosis and management of placenta percreta: a review. Obstet Gynecol Surv. 1998;53(8):509-17.
9. Comstock CH. Antenatal diagnosis of placenta accreta: a review. Ultrasound in Obstetrics and Gynecology. 2005;26(1):89-96.

10. Comstock CH, Love JJ, Bronsteen RA, Lee W, Vettraino IM, Huang RR. Sonographic detection of placenta accreta in the second and third trimesters of pregnancy. Am J Obstet Gynecol. 2004;190:113540.

11. ACOG Committee on Obstetric Practice Committee opinion no. 266: placenta accreta. Obstet Gynecol. 2002;99:169-70.

12. Eller AG, Bennett MA, Sharshiner M, Masheter C, Soisson AP, Dodson M, et al. Maternal morbidity in cases of placenta accreta managed by a multidisciplinary care team compared with standard obstetric care. Obstet Gynecol. 2011;117:331-7.

13. Arnadottir BT, Hardardóttir H, Marvinsdóttir B. Case report seventeen year old primipara with placenta increta treated with methotrexate. Laeknabladid. 2008;94(7-8):549-52.

14. Kinoshita T, Ogawa K, Yasumizu T, Kato J. Spontaneous rupture of the uterus due to placenta percreta at 25-weeks of gestation: a case report. J Obstetr Gynecol Res. 1996;22(2):125-8.

15. Rajkumar B, Kumar N, Srinivasan S. Placenta percreta in primigravida, an unsuspected situation. Int $\mathbf{J}$ Reproduct Contracept Obstet Gynecol. 2016;3(1):239-41.

Cite this article as: Vaidya A, Panchbudhe S, Satia M. Conservative management in a case of retained adherent placenta in a primigravida patient. Int $\mathrm{J}$ Reprod Contracept Obstet Gynecol 2017;6:3188-91. 